\title{
Penguatan Pembelajaran PKBM Putro Wali dengan Model Lesson Study di Ponpes Nurul Ulum Tagrineh Manoan Kecamatan Kokop Kabupaten Bangkalan
}

\author{
${ }^{1}$ Ali Nurhadi, Atiqullah, dan Hilmi Qosim Mubah \\ Institut Agama Islam Negeri Madura \\ 1'www.nurhadibk@gmail.com
}

\begin{abstract}
The Putro Wali Community Learning Center (PKBM) at the Nurul Ulum Tagrineh Manoan Ponpes District of Kokop District of Bangkalan needs to be strengthened, including the Lesson Study model consisting of plan, do, and see. The results are proven to be able to provide reinforcement of learning among enthusiastic teachers and will continue to apply after the implementation of PKM. The lesson study model as one of the learning development models for teachers is interesting to do. Aside from being a means of friendship, it also makes learning more interesting because it is thought together through a plan (planning), including in making learning implementation plans (RPP). Furthermore, at the do (implementation) stage, that is what has been planned to be carried out by the model teacher that was agreed upon during the planning. While other teachers become observers while noting things that are found. The next activity is see (reflection) by evaluating together under the coordination of the model teacher. When students do in this case the students at PKBM Putro Wali become fun, because they are observed and can interact with teachers who may not have been met while learning at PKBM. The student is also serious because many teachers see the learning process in PKBM so that it can also be motivated and can be called shock therapy.
\end{abstract}

Keywords: strengthening learning; lesson study; PKBM

\begin{abstract}
Abstrak
Pusat Kegiatan Belajar Masyarakat (PKBM) Putro Wali di Ponpes Nurul Ulum Tagrineh Manoan Kecamatan Kokop Kabupaten Bangkalan perlu diberikan penguatan, diantaranya dengan model Lesson Study yang terdiri dari plan, do, dan see. Hasilnya terbukti dapat memberikan penguatan pembelajaran diantarnya para guru antusias dan akan akan menerapkan secara kontinyu pasca pelaksanaan PKM. Model lesson study sebagai salah satu model pengembangan pembelajaran bagi guru yang menarik untuk dilakukan. Di samping sebagai sarana sillaturahim juga membuat pembelajaran semakin menarik disebabkan dipikirkan secara bersama melalui plan (perencanaan) termasuk dalam pembuatan rencana pelaksanaan pembelajaran (RPP). Selanjutnya pada tahap do (pelaksanaan) yaitu apa yang sudah direncanakan dilaksanakan oleh guru model yang sudah disepakati saat perencanaan. Sedangkan para guru lain menjadi pengamat sekaligus mencatat hal-hal yang ditemukan. Kegiatan selanjutnya adalah see (refleksi) dengan mengevaluasi secara bersama-sama dibawah koordinasi guru model. Pada saat do siswa dalam hal ini si pebelajar di PKBM Putro Wali menjadi menyenangkan, karena mereka diamati serta dapat merinteraksi dengan para guru yang mungkin belum pernah ditemui saat pembelajaran di PKBM. Si pebelajar juga bersungguh-sungguh sebab banyak guru yang melihat proses pembelajaran di PKBM sehingga juga menjadi motivasi sekaligus bisa disebut shock terapi.
\end{abstract}

Kata kunci: penguatan pembelajaran; lesson study; PKBM

\section{Pendahuluan}

Pusat Kegiatan Belajar Masyarakat (PKBM) adalah lembaga yang dibentuk oleh masyarakat untuk masyarakat yang bergerak dalam bidang pendidikan. PKBM ini masih berada di bawah pengawasan dan bimbingan dari Dinas Pendidikan Nasional. 
PKBM ini bisa berupa tingkat desa ataupun kecamatan. Untuk mendirikan PKBM bisa dari unsur apapun oleh siapapun yang tentunya telah memenuhi syarat-syarat kelembagaan antara lain : 1) Akta Notaris; 2) NPWP; 3) Susunan Badan pengurus; 4) Sekretariat; 5) Izin Operasional dari Dinas Pendidikan Kab/kota ${ }^{1}$

PKBM sebagai salah satu pendidikan nonformal yang keberadaannya sangat dibutuhkan di masyarakat. Hal ini disebabkan masih banyak anggota masyarakat yang belum dapat menyelesaikan studi lewat jalur formal seperti pada tingkat SD/MI, SMP/MTs, SMA/SMK/MA. Di samping itu masih banyak anggota masyarakat khususnya di pedesaan yang belum bisa membaca. Oleh sebab itu keberadaan PKBM sebagai wadah yang sangat sesuai.

Dalam UUSPN Tahun 2003 Pasal 1 ayat (12) yang dimaksud dengan Pendidikan nonformal adalah jalur pendidikan di luar pendidikan formal yang dapat dilaksanakan secara terstruktur dan berjenjang. Pendidikan nonformal meliputi pendidikan kecakapan hidup, pendidikan anak usia dini, pendidikan kepemudaan, pendidikan pemberdayaan perempuan, pendidikan keaksaraan, pendidikan keterampilan dan pelatihan kerja, pendidikan kesetaraan, serta pendidikan lain yang ditujukan untuk mengembangkan kemampuan peserta didik. ${ }^{2}$

PKBM sebagai salah satu pendidikan nonformal yang memfasilitasi kebutuhan masyarakat. Keberadaan PKBM menjadi penggerak utama dalam meningkatkan kualitas pendidikan bahkan ekonomi masyarakat. Septiani dalam Irmawati menyebutkan bahwa dalam memfasilitasi belajar masyarakat, PKBM mempunyai tugas dan fungsi sebagai berikut: 1) mengidentifikasi kebutuhan masyarakat, 2) menyelenggarakan program pendidikan, 3) menyediakan sumber daya potensial, 4) membangun kerja sama dengan mitra, 5) memonitoring dan mengevaluasi program, 6) pendidikan alternatif, 7) pusat informasi dan sumber belajar, dan 8) pengembangan masyarakat. $^{3}$

Salah satu program PKBM adalah menyelenggarakan pendidikan. Kegiatan dilaksanakan setelah keberadaan PKBM terwujud. Akan tetapi faktanya banyak keberadaan PKBM kurang efektif meskipun sudah ada ijin operasioanlnya, seperti yang terjadi pada PKBM Putro Wali yang berada di Desa Dupok Kecamatan Kokop Kabupaten Bangkalan.

Untuk memfasilitasi masyarakat belajar sepanjang hayat, maka PKBM perlu melakukan perencanaan atau mendesain instruksional, yaitu menganalisis kebutuhan masyarakat, merancang program pembelajaran; mengembangkan bahan strategi, serta sumber belajar yang beraneka ragam; mengimplementasikan bahan, metode pembelajaran, dan berbagai sumber belajar dalam proses pembelajaran; serta melakukan evaluasi secara berkala.

Perubahan untuk pengelolaan juga harus terus dilakukan. Perubahan suatu organisasi karena adanya globalisasi yang terus berjalan. Lembaga pendidikan, sekolah atau madrasah juga merupakan organisasi tentunya perlu terus menyesuaikan dengan melakukan perubahan-perubahan akibat adanya globalisasi. Dengan demikian eksistensi organisasi akan tetap terjaga bahkan dapat berkembang ${ }^{4}$

Winardi menyatakan bahwa perubahan senantiasa mengandung makna beralihnya keadaan sebelumnya (the best condition) menjadi keadaan setelahnya (the after condition $)^{5}$. Hal ini senada dengan pendapat Potts dan La Marsh melihat bahwa

${ }^{1}$ https://id.wikipedia.org/wiki/Pusat_Kegiatan_Belajar_Masyarakat

${ }^{2}$ UUSPN Tahun 2003 Pasal 27 ayat 3.

3/rmawatii. 2017. Peran Pusat Kegiatan Belajar Masyarakat (PKBM) dalam Mengurangi Buta Aksara di Kabupaten Karimun. Jurnal Pendidikan dan Kebudayaan, 2 (1), 81-98.

4 Ali Nurhadi, "Perubahan Organisasi Bagi Pengelola Madrasah Dalam Menghadapi Persaingan Global," AL-FIKRAH 1, no. 1 (2018): 16-27.

${ }^{5}$ J. Winardi, Manajemen Perubahan (Management of Change) (Bandung: Kencana Prenada Group, 2004), hlm 42-44. 
perubahan merupakan pergeseran dan keadaan sekarang dari suatu organisasi menuju pada keadaan yang didinginkan di masa depan ${ }^{6}$.

Oleh sebab itu dibutuhkan pengelola PKBM yang profesional dan mampu menjaga eksistensi serta program yang telah direncanakan sehingga keberadaan PKBM sangat bermanfaat bagi masyarakat. Di sisi lain pembinaan pengelola PKBM secara langsung belum sepenuhnya dilakukan oleh pemerintah sehingga dibutuhkan penguatan dari berbagai pihak termasuk Perguruan Tinggi sebagai wujud pelaksanaan pengabdian kepada masyarakat.

Berdasarkan wawancara awal dengan pengelola salah satunya perlu penguatan dalam proses pembelajaran. Disebabkan guru yang membimbing beraneka ragam profesinya. Warga belajar PKBM rata-rata sudah dewasa khususnya untuk tingkat mahir yang setara dengan Paket $C$. Jika metode pembelajaran disamakan dengan proses pembelajaran SMA sederajat juga kurang sesuai karena ada yang sudah berusia layaknya mahasiswa? ${ }^{7}$.

Oleh sebab itu di sini perlu penguatan proses pembelajaran agar keberadaan PKBM Putro Wali tetap eksis. Pemberdayaan PKBM Putra Wali dengan penguatan pada aspek pembelajaran dengan harapan sebagai pintu utama untuk melaksanakan semua program yang telah direncanakan khususnya pada peningkatan mutu pendidikan ${ }^{8}$. Harapannya akan berdampak pada kesejateraan disebabkan mereka dapat memiliki legalitas ijazah yang disetarakan dengan SD, SMP dan SMA. Berdasarkan identifikasi masalah ditentukan rumusan masalah seperti berikut ini: 1) Bagaimanakah meningkatkan kemampuan para guru pengajar di PKBM Putro Wali dengan berbagai latar belakang berbeda dengan model lesson study?; 2) Bagaimanakah meningkatkan mutu pembelajaran di PKBM Putro Wali dengan adanya model Lesson Study?; 3) Bagaimanakah meningkatkan motivasi dan keberanian para pebelajar di PKBM Putro Wali sebab adanya kolaborasi dengan berbagai pihak dengan model lesson study?

Secara umum tujuan pendampingan dan pembinaan pada PKBM Putro Wali adalah memampukan dan memandirikan masyarakat PKBM ini agar berfungsi sesuai program pemerintah khususnya dalam bidang pendidikan. Di samping itu dengan keberadaan PKBM yang semakin kuat dapat dikembangkan pada bidang lain untuk penguatan ekonomi dan kesejahteraan warga belajar khusunya pada penguatan keterampilannya.

Adapun secara khusus tujuan pendampingan sesuai rumusan masalah sebagai berikut. 1) Meningkatkan kemampuan para guru pengajar di PKBM Putro Wali dengan berbagai latar belakang berbeda dengan model lesson study; 2) Meningkatkan mutu pembelajaran di PKBM Putro Wali dengan adanya model Lesson Study; 3) Meningkatkan motivasi dan keberanian para pebelajar di PKBM Putro Wali sebab adanya kolaborasi dengan berbagai pihak dengan model lesson study.

Kegiatan Pengabdian Kepada Masyarakat dengan tema "Penguatan Pembelajaran PKBM Putro Wali Dengan Model Lesson Study di Ponpes Nurul Ulum Tagrineh Manoan Kecamatan Kokop Kabupaten Bangkalan" memiliki manfaat kepada berbagai pihak seperti berikut ini; 1) Bagi PKBM Putro Wali sebagai upaya peningkatan mutu pembelajarannya; 2) Bagi Prodi MPI sebagai wahana mengembangkan prodi MPI serta wujud nyata pengabdian dosen MPI kepada masyarakat; 3) Bagi LP2M sebagai bahan untuk dihasilkannya produk pengabdian kepada masyarakat yang dapat dipublikasikan untuk kemajuan masyarakat.

\footnotetext{
${ }^{6}$ R. Potts, \& marsh, J.L, Managing Change for Success (London: Duncan Baird Publishers, 2004), hlm 57-61.

${ }^{7}$ Wawancara dengan Sayadi sekretaris PKMB Putro Wali

${ }^{8}$ Prof Dr H. Andi Rasyid Pananrangi M.Pd SH, Manajemen Pendidikan (Celebes Media Perkasa, 2017).
} 


\section{Metode Pelaksanaan}

Tempat dan sasaran pengabdian masyarakat adalah PKBM Putro Wali sebagai salah satu pendidikan nonformal yang lahir di Kecamatan Kokop tepatnya di Dusun Glepa Desa Dupok Kecamatan Kokop Kabupaten Bangkalan dengan NPSN P9934448. Saat ini memiliki warga belajar tingkat dasar, terampil dan mahir dengan jumlah total 106 orang terdiri dari 90 laki-laki dan 16 perempuan serta memiliki mitra utama Ponpes Nurul Ulum Tagrineh Desa Manoan Kecamatan Kokop Kabupaten Bangkalan disebabkan siswa terbesar adalah para santri.

Sedangkan khalayak sasaran dari program pendampingan dan penguatan pembelajaran PKBM Putro Wali dengan model lesson study ini adalah para pengurus PKBM Putro Wali, guru pembelajar, para ustad yang menjadi guru atau siswa.

Pelaksanaan kegiatan dilakukan dengan $2 x$ pertemuan terdiri dari pertemuan pertama dengan menghadirkan para guru pengajar di PKBM Putro Wali serta para pengelolanya. Tujuan memberikan pemahaman desain model lesson study serta merencanakan pembelajaran dengan menentukan satu guru sebagai model. Sekaligus menyiapkan segala program kegiatan dan media pembelajarannya untuk kegiatan pelaksanaannya.

Selanjutnya dilakukan pertemuan kedua yaitu pada guru serta para siswa yang dipilih sebagai masyarakat pebelajar di PKBM putro Wali untuk diterapkan model lesson study sekaligus dilakukan refleksi. Sebelumnya didahului dengan penyampaian materi tentang penguatan pembelajaran di masyarakat oleh Dr. H. Atiqullah, M.Pd serta materi tentang lesson study oleh Dr. H. Ali Nurhadi, S.Pd.,M.Pd. Kegiatan penyampaian materi dilakukan sekaligus dengan Tanya jawab tanpa moderator.

Pelaksanaan kegiatan ini didasarkan pada metode yang digunakan untuk pendampingan dengan tujuan penguatan pembelajaran pada PKBM Putro Wali yaitu dengan model lesson study. Model ini merupakan suatu pendekatan peningkatan pembelajaran yang awal mulanya dikembangkan di Jepang. Lesson study adalah suatu proses kolaboratif dimana sekelompok guru mengidentifikasi suatu masalah pembelajaran dan merancang suatu skenario pembelajaran (tahap plan), membelajarkan siswa sesuai skenario yang dilakukan salah seorang guru, sementara yang lain mengamati (tahap do), merefleksi dan mengevaluasi (tahap see), serta merevisi skenario pembelajaran ${ }^{9}$.

Lesson study dipandang efektif menguatkan pembelajaran di PKBM Putro Wali disebabkan guru bersama-sama melakukan penguatan proses dimulai dengan perencanaan dengan membuat RPP atau skenario pembelajaran. Dilanjutkan dengan pelaksanaan serta refleksi terhadap kegiatan pembelajaran yang dilakukan. Dosen dapat berperan sebagai fasilitator atau narasumber bahkan menjadi model jika memang dibutuhkan.

Model lesson study yang dilakukan akan berdampak secara langsung pada proses pembelajaran berikutnya. Sebab sudah ada standar yang harusnya dilakukan oleh PKBM Putro Wali sehingga peserta didik atau warga belajar menjadi senang dalam proses pembelajarannya.

\section{Hasil dan Pembahasan}

\section{A. Hasil Pelaksanaan Kegiatan}

Pelaksanaan kegiatan pengabdian kepada masyarakat dengan tema "Penguatan Pembelajaran PKBM Putro Wali Dengan Model Lesson Study di Ponpes Nurul Ulum Tagrineh Manoan Kecamatan Kokop Kabupaten Bangkalan" dijadwalkan dengan dua kali pertemuan sesuai dengan rencana. Pelaksanaannya

\footnotetext{
${ }^{9}$ Siti Zubaidah 2010. Lesson Study Sebagai Salah Satu Model Pengembangan Profesionalisme Guru. Makalah Disampaikan pada Pendidikan dan Pelatihan Nasional dengan Tema Peningkatan Profesionalisme Guru melalui Kegiatan Lesson Study, 22 April 2010 di Universitas Brawijaya Malang
} 
di Ponpes Nurul Ulum Tagrineh Manoan Kecamatan Kokop Kabupaten Bangkalan pada hari Kamis dan Jumat tanggal 18-19 Juli 2019.

Adapun secara sistematis rangkaian kegiatan sesuai dengan waktu seperti tercantum dalam Tabel 1.1 beikut ini.

Tabel 1.1 Jadwal Kegiatan Penguatan Pembelajaran PKBM Putro Wali Dengan Model Lesson Study di Ponpes Nurul Ulum Tagrineh Manoan Kecamatan Kokop Kabupaten Bangkalan

\begin{tabular}{|c|c|c|c|}
\hline Hari/tanggal & Waktu & Kegiatan & Petugas/Fasilitator \\
\hline $\begin{array}{l}\text { Kamis, } \\
18 \text { Juli } 2019\end{array}$ & $\begin{array}{r}08.00-09.00 \\
09.00-12.00 \\
12.00-13.00 \\
13.00-15.00\end{array}$ & \begin{tabular}{lr} 
Pengenalan Program \\
PKBM Putro Wali \\
Diskusi permasalahan \\
pembelajaran PKBM \\
Putro Wali dan \\
$\begin{array}{l}\text { Pendampingan dengan } \\
\text { Pengenalan Lesson Study }\end{array}$ \\
Ishoma \\
\multicolumn{2}{l}{ Penentuan Rencana } \\
Praktek Lesson Study dan \\
penentuan Model
\end{tabular} & $\begin{array}{l}\text { Dr. H. Ali Nurhadi, } \\
\text { S.Pd.,M.Pd. } \\
\text { Panitia } \\
\text { Dr. H. Ali Nurhadi, } \\
\text { S.Pd.,M.Pd. } \\
\text { Dr. H. Atiqullah, } \\
\text { S.Ag.,M.Pd }\end{array}$ \\
\hline $\begin{array}{l}\text { Jumat } \\
19 \text { Juli } 2019\end{array}$ & $\begin{array}{l}07.00-07.30 \\
07.30-08.00\end{array}$ & $\begin{array}{l}\text { Registrasi Peserta } \\
\text { Pembukaan }\end{array}$ & $\begin{array}{l}\text { Panitia } \\
\text { Korwil Pendidikan Kec. } \\
\text { Kokop. Pengurus PKBM } \\
\text { Putro Wali. }\end{array}$ \\
\hline & $\begin{array}{r}08.00-10.00 \\
10.00-11.00 \\
11.00-13.00 \\
13.00-14.00 \\
14.00-16.00 \\
16.00-16.30\end{array}$ & 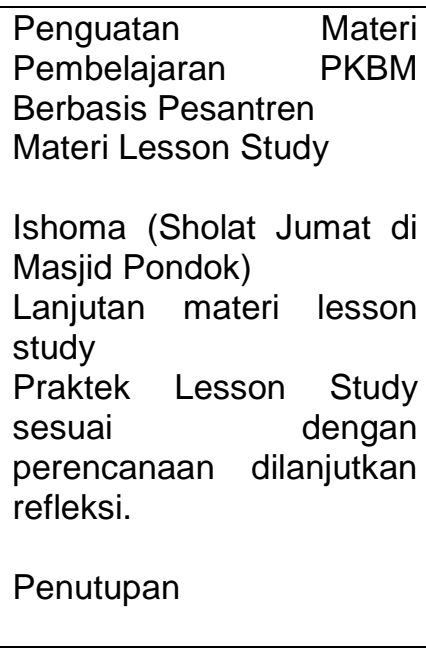 & $\begin{array}{l}\text { Dr. H. Atiqullah, } \\
\text { S.Ag.,M.Pd } \\
\text { Dr. H. Ali Nurhadi, } \\
\text { S.Pd.,M.Pd. } \\
\text { Panitia } \\
\\
\text { Dr. H. Ali Nurhadi, } \\
\text { S.Pd.,M.Pd. } \\
\text { Panitia dan fasilitator }\end{array}$ \\
\hline
\end{tabular}

Pelaksanaan pengabdian dengan $2 x$ pertemuan. Pertemuan pertama menguatkan para guru dan pelaksana untuk kegiatan KBM dengan pengenalan konsep lesson study sebagai model pembinaan profesi. Lesson study dipandang sebagai model yang efektif sebab sebagai sarana untuk belajar bersama. Kegiatan diawali dengan penyampaian teori sekaligus aksi dengan melakukan plan (perencanaan). Kegiatan ini dilakukan bersama guru untuk membuat perencanaan bersama tentang pembelajaran yang akan dilakukan.

Kegiatan perencanaan diwarnai usulan dan pendapat para guru dengan berbagai pengalaman masing-masing. Di samping itu juga didasarkan pada program kegiatan yang ada di PKBM Putro Wali. Dalam perencanaan juga 
ditentukan guru model yang akan mempraktekkan dan diamati oleh peserta lain sebagai wujud do (pelaksanaan).

Penentuan guru model juga menjadi kendala karena mereka tidak terbiasa diamati dalam pembelajaran. Akhirnya diputuskan salah satu guru model sebagai guru di PKBM Putro Wali, yaitu Bapak Mohammad Fatah, S.Pd mantan pengawas Kecamatan Kokop yang sudah purna tugas dan mengabdikan diri di PKBM ini.

Kegiatan berikutnya tanggal 19 Juli 2019 dilakukan penguatan kembali materi tentang lesson study. Setelah itu dilakukan sholat jumat di masjid dalam pondok pesantren. Selesai itu dilakukan praktek pelaksanaan lesson study bagi guru model serta dilakukan pengamatan oleh observer yang mengikuti kegiatan perencanaan. Kegiatan dilanjutkan dengan see sebagai bentuk refleksi yang dilakukan observer bersama guru model.

Dalam kegiatan refleksi beberapa tremuan observer juga disampaikan untuk menguatkan pembelajaran. Kegiatan refleksi juga sebagai sarana belajar bersama dan intropeksi bagi guru model. Meskipun sudah memiliki pengalaman pembelajaran yang sangat lama guru model juga mendapat banyak masukan, seperti terlalu cepat mengajarnya, kurang menarik karena hanya mendekte dan berceramah saja padahal diperencanaan sudah didesain untuk diskusi dan praktek.

\section{B. Pembahasan Hasil Pelaksanaan Kegiatan}

Kegiatan Pengabdian Kepada Masyarakat dengan tema "Penguatan Pembelajaran PKBM Putro Wali Dengan Model Lesson Study di Ponpes Nurul Ulum Tagrineh Manoan Kecamatan Kokop Kabupaten Bangkalan" telah dilaksanakan selama $2 x$ pertemuan. Pertemuan pertama sebagai perencanaan sekaligus koordinasi dan mempersiapkan baik secara teknis maupun teoritis terkait dengan model lesson study khususnya pada tahapan plan. Kegiatan ini dilakukan pada hari Kamis, 17 Juli 2019 dengan menghadirkan para pengurus PKBM dan guru inti PKBM sekaligus ditentukan model setelah disosialisaikan gagasan tentang lesoon study.

Kegiatan pada pertemuan pertama sangat menyenangkan khususnya bagi para pengurus PKBM serta guru inti yang berasal dari para ustad atau pengawas tetapi sudah purna tugas (Bapak Fatah). Kegiatan ini merupakan kegiatan pertama kali setelah purna disamping itu bagi para ustad merupakan hal yang baru atau pengalaman baru bagi mereka. Pembelajaran bersama mengasikan sebab mendesain pembelajaran yang dilakukan secara bersama sehingga ada pemikiran bersama untuk merencanakan sampai pada melaksanakannya.

Perencanaan pembelajaran didesain bersama yang selama ini belum pernah dilakukan. Di pondok pesantren pembelajaran juga dilakukan tanpa ada perencanaan sehingga langsung dikasanakan. Misalnya membahasa kitab dengan jadwal hari maka pembelajarannya berlanjut saja dengan model yang tetap, yaitu kita membaca menjelaskan para santri menyimak, sehingga tidak tahu apakah para santri senang, memahami, jenuh atau apa yang mereka ingunkan. Dengan perencanaan yang jelas pembelajaran dapat dianalisis apa sebenarnya yang ingin dicapai dan bagaimana respon siswa.

Selanjutnya untuk pertemuan kedua dilakukan bersama para pebelajar tetapi tidak keseluruhan bersama para guru di PKBM Putro Wali dengan berbagai latar belakang yang berbeda. Ada yang berasal dari ustad, pensiunan pengawas, guru dan kepala sekolah, staf di UPTD SMPN Kokop, Staf Koordinator wilayah pendidikan Kecamatan Kokop. Kegiatan ini dilakukan di Ponpes Nurul Ulum Tagrineh Manoan Kecamatan Kokop Kabupaten Bangkalan pada Hari Jum'at 19 Juli 2019.

Ponpes Nurul Ulum Tagrineh Manoan Kecamatan Kokop Kabupaten Bangkalan sebagai mitra utama PKBM Putro Wali . Hal ini disebabkan sebagian besar pebelajar (siswa) di PKBM Putro Wali adalah santri di ponpes ini. Pondok pesantren Nurul Ulum sebagai pondok salafi sehingga tidak memiliki ijazah yang 
secara legalitas diakui untuk melanjutkan study bagi para santri sampai pada perguruan tinggi. Pondok pesantren nurul ulum memiliki santri yang banyak. Ditengah pondok terdapat masjid. Dengan mengikuti pembelajaran di PKBM Putro Wali maka akan memiliki ijazah yang disetarakan pada paket B (SMP), atau C (setingkat SMA).

Pada dasarnya pendekatan pendampingan yang dilakukan pada PKBM Putra Wali dengan tetap berpijak pada penguatan kompetensi pembelajaran pada para guru di PKBM Putro Wali. Mereka diberdayakan dengan model Lesson Study. Kegiatan dapat dilakukan dengan beberapa tahap dengan memberdayakan para guru di PKBM menjadi model. Harapanya mereka dapat mengembangkan sendiri jika ada beberapa guru baru.

Penguatan pembelajaran dengan lesson study dipandang efektif untuk PKBM Putro Wali disebabkan dapat menguatkan secara langsung kompetensi mereka tanpa melibatkan PKBM yang lain. Kegiatan lesson study dapat terus dikembangkan untuk penguatan pembelajarannya. Harapannya proses pembejaran dapat berjalan dengan baik dan hasilnya nyata serta berdampak pada tingkat kesejahteraan secara langsung dan tidak langsung. Secara langsung dengan menyelipkan berbagai program pemberdayaan ekonomi dan secara tidak langsung mereka dapat menyelesaikan program belajarnya dengan mendapatkan sertifikat yang legalitasnya disamakan dengan SD/SMP/SMA sederajat.

Kegiatan pendampingan penguatan pembelajaran dengan lesson study dipandang sangat menyenangkan untuk PKBM Putro Wali disebabkan pertama kali kegiatan ini dilakukan dan memperoleh pengalaman yang menyenangkan khususnya bagi pengelola PKBM. Bagi siswa merupakan hal yang baru dalam berkolaborasi dan berinteraksi dengan berbagai pihak. Bagi pondok pesantren mendapatkan berbagai informasi baru berhubungan dengan PKBM serta pendidikan secara umum.

Pada dasarnya upaya ini merupakan profesionalisasi bagi guru dan pengelola PKBM. Profesionalisasi pada dasarnya adalah upaya yang dilakukan secara terus menerus bagi penyandang profesi untuk senantiasa meningkatkan kemampuan profesinya (continous provessional development) ${ }^{10}$

Kegiatan Pengabdian Kepada Masyarakat dengan tema "Penguatan Pembelajaran PKBM Putro Wali Dengan Model Lesson Study di Ponpes Nurul Ulum Tagrineh Manoan Kecamatan Kokop Kabupaten Bangkalan dapat dilaksanakan dengan baik disebabkan adanya beberapa faktor pedukung, diantaranya: 1) Pengurus PKBM menginginkan adanya pembaruan untuk kemajuan PKBM yang dikelola sehingga komunikasi untuk pelaksanaan pengabdian kepada masyarakat mudah dilakukan meskipun via telp atau WA sehingga jarak tidak menjadi kendala; 2) Pengasuh Ponpes Nurul Ulum Tagrineh Manoan Kecamatan Kokop Kabupaten Bangkalan sebagai mitra utama PKBM Putro Wali sangat mendukung dengan memfasilitasi tempat untuk kegiatan serta fasilitas lain seperti adanya masjid dan sarananya toilet, kamar mandi dengan ketersediaan air yang sangat cukup (disebab di Kokop adalah daerah kekeringan); 3) Para guru PKBM antusias untuk mengikuti program ini disebabkan sebagai hal yang baru dibuktikan kehadiran mereka untuk para guru di PKBM Putro Wali mencapai $100 \%$.

Di samping ada banyak faktor pendukung juga ada faktor penghambat dalam pelaksanaan Pengabdian Kepada Masyarat (PKM) di Ponpes Nurul Ulum Tagrineh Manoan Kecamatan Kokop Kabupaten Bangkalan sebagai mitra PKBM Putro Wali diantaranya:1) Guru dengan latar belakang para ustad dan juga dulu sebagai alumni PKBM Putro Wali cukup lambat dalam memahami konsep lesson

10 "Profesi Keguruan (Dr. Ali Nurhadi, S.Pd, M.Pd) | Penerbit Goresan Pena (Anggota IKAPI)," accessed August 4, 2019, https://www.goresanpena.co.id/2017/02/profesi-keguruan-dr-alinurhadi-spd-mpd.html. 
study sehingga harus diulang dalam penanamannya yang berdampak pada waktu; 2) Kesulitan untuk menentukan guru model karena para guru di PKBM Putro Wali ini merasa malu.

\section{Penutup}

\section{A. Simpulan}

Berdasarkan pelaksanakan Pengabdian Kepada Masyarakat (PKM) dengan tema "Penguatan Pembelajaran PKBM Putro Wali Dengan Model Lesson Study di Ponpes Nurul Ulum Tagrineh Manoan Kecamatan Kokop Kabupaten Bangkalan dapat dilaksanakan dengan baik sesuai prosedur karena dukungan dan partisipasi para pengelola PKBM Putro Wali yang menginginkan kemajuan pada Pusat Kegiatan Belajar Masyarakat yang dikelolanya.

Adapun hasil temuannya menunjukkan pelaksanakan Pengabdian Kepada Masyarakat (PKM) disimpulkan Model Lesson Study yang terdiri dari plan, do, dan see dapat memberikan penguatan pembelajaran PKBM Putro Wali di Ponpes Nurul Ulum Tagrineh Manoan Kecamatan Kokop Kabupaten Bangkalan dibuktikan para guru antusias dan akan akan menerapkan secara kontinyu pasca pelaksanaan PKM. Sebelumnya secara umum pembelajaran di PKBM belum berjalan dengan maksimal. Siswa akan penuh ketika akan terjadi ujian. Hal ini disebabkan kurang menariknya proses pembelajaran yang ada dengan berbagai faktor penyebab seperti latar belakang para guru, para si pebelajar, dan kesibukannya. Oleh sebab itu perlu kegiatan pembelajara yang menarik dan dapat memotivasi mereka secara langsung.

Model lesson study sebagai salah satu model pengembangan pembelajaran bagi guru yang menarik untuk dilakukan. Di samping sebagai sarana sillaturahim juga membuat pembelajaran semakin menarik disebabkan dipikirkan secara bersama melalui plan (perencanaan) termasuk dalam pembuatan rencana pelaksanaan pembelajaran (RPP). Selanjutnya pada tahap do (pelaksanaan) yaitu apa yang sudah direncanakan dilaksanakan oleh guru model yang sudah disepakati saat perencanaan. Sedangkan para guru lain menjadi pengamat sekaligus mencatat hal-hal yang ditemukan. Kegiatan selanjutnya adalah see (refleksi) dengan mengevaluasi secara bersama-sama dibawah koordinasi guru model.

Pada saat do siswa dalam hal ini si pebelajar di PKBM Putro Wali menjadi menyenangkan, karena mereka diamati serta dapat merinteraksi dengan para guru yang mungkin belum pernah ditemui saat pembelajaran di PKBM. Si pebelajar juga bersungguh-sungguh sebab banyak guru yang melihat proses pembelajaran di PKBM sehingga juga menjadi motivasi sekaligus bisa disebut shock terapi.

\section{B. Rekomendasi}

Berdasarkan temuan pada kegiatan pelaksanakan Pengabdian Kepada Masyarakat (PKM) dengan tema "Penguatan Pembelajaran PKBM Putro Wali Dengan Model Lesson Study di Ponpes Nurul Ulum Tagrineh Manoan Kecamatan Kokop Kabupaten Bangkalan direkomendasikan sebagai berikut; 1) Pentingnya pengabdian kepada masyarakat berbasis pendidikan non formal seperti PKBM harus terus dilaksanakan sebab jarang mendapat sentuhan pengembangan sedangkan keberadaannya berhubungan langsung dengan masyarakat. Penguatan yang sifatnya aplikatif seperti lesson study juga perlu diberikan; 2) Perlunya pemahaman sekaligus implementasi secara nyata dari hal yang terkecil bagi pengelola PKBM sehingga mutu PKBM dapat terus ditingkatkan seperti penerapan lesson study; 3) Perlu adanya kerja sama antar pengelola PKBM untuk meningkatkan mutu sehingga model lesson study dapat dikembangkan lintas PKBM; 4) PKBM Putro Wali hendaknya terus melakukan lesson study meskipun tanpa program PKM dari perguruan tinggi misalnya dalam satu semester atau satu 
tahun sekali dilaksanakan agar pemahaman dan penguatan pembelajaran tetap berjalan serta berkembang.

Berdasarkan simpulan dan rekomendasi pada kegiatan pelaksanakan Pengabdian Kepada Masyarakat (PKM) dengan tema "Penguatan Pembelajaran PKBM Putro Wali Dengan Model Lesson Study di Ponpes Nurul Ulum Tagrineh Manoan Kecamatan Kokop Kabupaten Bangkalan sesuai rekomendasi disarankan pada berbagai pihak sebagai berikut; 1) PKBM Putro Wali hendaknya terus melakukan lesson study meskipun tanpa program PKM dari perguruan tinggi misalnya dalam satu semester atau satu tahun sekali dilaksanakan agar pemahaman dan penguatan pembelajaran tetap berjalan serta berkembang; 2) Bagi LP2M pentingnya pengabdian kepada masyarakat berbasis pendidikan non formal seperti PKBM hendaknya terus dilaksanakan sebab jarang mendapat sentuhan pengembangan sedangkan keberadaannya berhubungan langsung dengan masyarakat. Penguatan yang sifatnya aplikatif seperti lesson study atau program lainnya juga perlu diberikan; 3) Bagi Dinas Bidang Pendidikan Luar Sekolah dan Pengelola Pondok Pesantren hendaknya dijalin kerja sama khususnya dengan perguruan tinggi untuk penguatan program pendidikan non formalnya.

\section{Daftar Pustaka}

https://id.wikipedia.org/wiki/Pusat Kegiatan Belajar Masyarakat

Irmawatii. 2017. Peran Pusat Kegiatan Belajar Masyarakat (PKBM) dalam Mengurangi Buta Aksara di Kabupaten Karimun. Jurnal Pendidikan dan Kebudayaan, 2 (1), 81-98.

M.Pd, Prof Dr H. Andi Rasyid Pananrangi, SH. Manajemen Pendidikan. Celebes Media Perkasa, 2017.

Nurhadi, Ali. "Perubahan Organisasi Bagi Pengelola Madrasah Dalam Menghadapi Persaingan Global." AL-FIKRAH 1, no. 1 (2018): 16-27.

"Profesi Keguruan (Dr. Ali Nurhadi, S.Pd, M.Pd) | Penerbit Goresan Pena (Anggota IKAPI)." Accessed August 2019. https://www.goresanpena.co.id/2017/02/profesi-keguruan-dr-ali-nurhadi-spdmpd.html.

R. Potts, \& marsh, J.L, Managing Change for Success (London: Duncan Baird Publishers, 2004), hlm 57-61.

Siti Zubaidah 2010. Lesson Study Sebagai Salah Satu Model Pengembangan Profesionalisme Guru. Makalah Disampaikan pada Pendidikan dan Pelatihan Nasional dengan Tema Peningkatan Profesionalisme Guru melalui Kegiatan Lesson Study, 22 April 2010 di Universitas Brawijaya Malang

UU Nomor 20 Tahun 2003 Tentang Sistem Pendidikan Nasional..

Winardi, J. 2004. Manajemen Perubahan (Management of Change). Bandung: Kencana Prenada Group. 